\title{
Asperger syndrome and criminal behaviour $^{\dagger}$
}

\author{
Kalpana Dein \& Marc Woodbury-Smith
}

\begin{abstract}
SUMMARY
The importance of considering antisocial behaviour among people with autism-spectrum disorders is apparent from the significant number of case reports and case series describing criminal behaviour of people with a diagnosis of Asperger syndrome. The evidence so far does not support a specific association between the syndrome and criminal offending. However, a small yet significant number of offenders with autism who engage in illegal behaviour find themselves socially excluded or detained in secure provisions for prolonged periods. This article gives an overview of the scant empirical evidence relating to criminality within the context of Asperger syndrome, and offers suggestions for managing the syndrome in mentally disordered offenders.
\end{abstract}

\section{DECLARATION OF INTEREST}

None.

Autism-spectrum disorders are a group of biologically based behavioural syndromes of childhood onset that are characterised by qualitative impairments in reciprocal social interaction and verbal and non-verbal communication, together with a restricted and repetitive range of behaviours, interests and activities - the so-called 'triad of impairments' (Wing 1981). Among individuals with 'high-functioning autism', the term 'Asperger syndrome' is reserved for people for whom the social interaction and restricted patterns of behaviour occur in the context of normal early language and cognitive development. Although people with Asperger syndrome do not have the communication impairments typical of autistic disorder, a number of specific pragmatic abnormalities are recognised (for further discussion see Klin 2005).

The syndrome itself was first described by the Viennese paediatrician Hans Asperger in 1944. Diagnostic features of the syndrome, however, were not operationalised until ICD-10 (World Health Organization 1992) and DSM-IV (American Psychiatric Association 1994).

The scientific literature concerned with autismspectrum disorders has increased enormously over the past two decades, although much of it has been concerned with the basic sciences rather than everyday clinical issues (summarised in Klin 2005). More specifically, very little has focused on people with autism who come into contact with the criminal justice system.

Offending and antisocial behaviour in the context of Asperger syndrome have been described in a number of case reports and case series (WoodburySmith 2005; Mouridsen 2008). Asperger himself, in his original paper, described antisocial behaviour in addition to the core clinical impairments (Frith 1991). Wing (1981: p. 116) similarly made reference to a small minority with a history of 'bizarre antisocial acts' in her case series of 34 children and adults with Asperger syndrome.

\section{Prevalence in forensic populations}

A study in Broadmoor Hospital, one of England's three high-security psychiatric hospitals, estimated that $1.5-2.3 \%$ of the hospital's male population had Asperger syndrome or autism-spectrum disorder (if equivocal cases were included) (Scragg 1994). This significantly exceeds the $0.36 \%$ prevalence estimated for the general population using the same criteria (Allen 2007). This overrepresentation of Asperger syndrome (at least 1.68\%, $n=22$ ) was subsequently confirmed in all three English high secure units (Hare 1999). In a sample of 72 men referred to the dangerous severe personality disorder unit of Her Majesty's Prison Whitemoor, two prisoners were given a definite diagnosis of Asperger syndrome and four a provisional diagnosis (in the absence of parental accounts), suggesting a prevalence of 2.7-8.3\%. A further four men showed autistic traits (Hawes 2003). Interestingly, much lower prevalences, of $0.46 \%$ in secure psychiatric units and $0.93 \%$ in the prison service, have been reported in Scotland (Myers 2004).

In contrast to these UK estimates, in a group of Swedish young offenders referred for forensic assessments in Stockholm, 15\% were diagnosed with a definite autism-spectrum disorder and a further $12 \%$ with a probable disorder of this type (Siponmaa 2001).

All of these findings are surprising, given that a Danish study found that the rate of conviction
Kalpana Dein is a consultant forensic psychiatrist working in Clare House (St Andrew's Healthcare, Essex, UK). She has a special interest in offenders with autistic disorders. She is pursuing an $\mathrm{MD}$ in Clinical Research at University College London, exploring high-functioning autism in mentally disordered offenders. Marc WoodburySmith is Assistant Professor in the Department of Psychiatry and Behavioural Neurosciences, McMaster University, Canada. He trained in psychiatry in Southampton and Cambridge in the UK, and at Yale University in the USA. During his time in Cambridge he completed his $\mathrm{PhD}$ thesis 'Exploring criminal behaviour among people with Asperger's disorder'

\section{Correspondence}

Marc Woodbury-Smith, McMaster University, Department of Psychiatry and Behavioural Neurosciences, Chedoke Site, Evel Building (Room 457), Hamilton, ON Canada L8N $3 Z 5$. Email: woodbur@mcmaster.ca

${ }^{\dagger}$ For a commentary on this article, see pp. 44-46, this issue. 
of people with Asperger syndrome was similar to that for people without $(P=0.89)$, and that the conviction rate of people with atypical autism was lower than that of people without $(P=0.14)$ (Mouridsen 2008). Similarly, a low rate of lawbreaking behaviour (using both self-report and official data) was found in a UK community sample of people with Asperger syndrome (WoodburySmith 2006).

Thus, the literature is difficult to interpret, but it seems reasonable to conclude that, even though the prevalence of the syndrome is higher than expected in forensic psychiatric populations, this does not reflect a raised rate of convictions, or indeed a raised rate of offending, in the community. Nevertheless, it is important for clinicians to be aware of autism-spectrum disorders in offenders. An early diagnosis and intervention may reduce the risk of future offending.

\section{The nature of the offences committed}

A wide variety of offences are represented in the literature. There is growing evidence that people with Asperger syndrome are more likely to commit fire-setting offences than people without the syndrome (Hare 1999; Siponmaa 2001; Mouridsen 2008). Both alcohol and drug misuse (SchwartzWatts 2005) and drug offences (Allen 2007) have been reported in this population, although substance use is comparatively rare (Murphy 2003; Woodbury-Smith 2006; Mouridsen 2008). Epidemiological studies indicate that people with Asperger syndrome do commit sexual offences (Hare 1999; Murphy 2003), but there is evidence that the rates of sexual offending in general (Hare 1999), and of child sex offences in particular (Elvish 2007), are lower among offenders with autism-spectrum disorders.

As regards violent offences, (self-)reported violence in a community sample was more common among those with Asperger syndrome (although

BOX 1 Factors that may mediate offending in Asperger syndrome

- General factors:
poor educational achievement
truancy
aggressive behaviour
hyperactivity/impulsivity
inattention
- Substance misuse is rare
- Social exclusion
- Late diagnosis

- Comorbid psychiatric conditions: conduct disorder antisocial personality disorder schizophrenia affective disorders (e.g. bipolar affective disorder, depression) attention-deficit hyperactivity disorder

- Neuropsychological impairment

- Circumscribed interests this result was not statistically significant) (Woodbury-Smith 2006), and there is evidence that offenders with autism-spectrum disorders are more likely to have previous convictions for assault (Elvish 2007). Similar rates of violent offending by patients with autism-spectrum disorders have been reported in high secure units in England (Hare 1999). However, a subsequent study in Broadmoor Hospital found that patients with Asperger syndrome had comparatively lower violence ratings for their index offence than did other patients (Murphy 2003).

\section{Characteristics of offenders}

A number of factors may mediate offending in people with Asperger syndrome (Box 1) and some of these are considered below.

\section{Gender}

As would be expected, the majority of offenders are men, although little is known about their socioeconomic status or ethnicity. Factors associated with the risk of offending in the general population, such as poor educational achievement, truancy, aggressive behaviour, hyperactivity/impulsivity and inattention (Woodbury-Smith 2006), may all be relevant in Asperger syndrome as well. Social exclusion is not an unusual experience for people with autism-spectrum disorders, and for a small minority feelings of powerlessness and resentment resulting from marginalisation may lead to malicious acts (Woodbury-Smith 2006).

A number of studies (e.g. Hare 1999; Mouridsen 2008 ) indicate that women with autism-spectrum disorders are more prone to antisocial behaviour than are other women. Crocombe et al (2006) found that 6 out of 51 women (over 10\%) in a high secure unit met ICD-10 criteria for an autism-spectrum disorder. The characteristics of female offenders with Asperger syndrome and the reasons for their apparent overrepresentation within criminal populations warrant further investigation.

\section{Comorbidity}

One of the few studies to have examined comorbidity among offenders with autism-spectrum disorders reported that none of its sample of male patients with Asperger syndrome in a high secure hospital had any history of serious antisocial behaviour or criminal convictions before the age of 18 (Murphy 2003). In contrast, $19 \%$ of another offender group with Asperger syndrome were tentatively diagnosed with antisocial personality disorder on the basis of their histories (Woodbury-Smith 2005). More studies are needed to test the robustness of this 
finding and to explore other relationships between comorbidity among offenders with autismspectrum disorders.

\section{Circumscribed interests and offending}

There is emerging support for a relationship between the pursuit of a circumscribed interest and offending. Circumscribed interests that are pursued with abnormal intensity are a core diagnostic feature of autism-spectrum disorders. Contact with the criminal justice system can occur as a result of stealing to pursue an interest or simply because of the antisocial nature of the interest itself (Scragg 1994; Wing 1997; Hare 1999; Woodbury-Smith 2009). Other characteristics of Asperger syndrome that have been linked to criminal offending include lack of empathy, social naivety (Wing 1997), unusual passivity and a lack of awareness of the outcome of an action (Royal College of Psychiatrists 2006).

\section{Contribution of neuropsychological impairments to antisocial behaviour}

Recent research has indicated that a number of neuropsychological impairments may also mediate risk of offending among people with autism-spectrum disorders. In one such study, we compared groups of adults with (a) autismspectrum disorders and a history of offending ('autism offender'), (b) autism-spectrum disorders and no history of offending ('autism non-offender') and (c) neither autism-spectrum disorders nor a history of offending ('non-autism non-offender') (Woodbury-Smith 2005). We found that, compared with the 'non-autism non-offender' group, the 'autism offender' group were impaired on tests of recognition of fear but not on tests of theory of mind or executive function. In contrast, and as would be expected from the literature, the 'autism non-offender' group were impaired on tests of theory of mind and executive function but only marginally impaired on fear recognition.

\section{Offenders with Asperger syndrome and psychopathy}

This finding of normal theory of mind alongside 'fear recognition impairment' led us to hypothesise that offenders may have comorbid psychopathy. Viding (2007) similarly noted that some individuals share the neurocognitive profile of both autism-spectrum disorder and psychopathy, although the majority of people with autism (even those with antisocial behaviour) do not share these characteristics.

Two studies using the Psychopathy Checklist Revised (PCL-R) reported contrasting results.

In the UK, Murphy (2007) found that none of the patients with Asperger syndrome at Broadmoor Hospital received an overall score on the PCL-R above the cut-off for psychopathy. Interestingly, in the different domains of the PCL-R these individuals frequently received higher scores on the affective component (including features such as lack of remorse or guilt, shallow affect, lack of empathy and failure to accept responsibility for one's actions) and lower scores on the other components than did a comparison group of the hospital's patients without Asperger syndrome. Both groups of patients received a comparable mean PCL-R score.

In Sweden, however, Soderstrom et al (2005) found that the total PCL-R scores, as well as scores on the 'unemotionality' and 'behavioural dyscontrol' factors, were significantly correlated with high-functioning autistic traits. The 'interpersonal' factor of the PCL-R showed none of these correlations, leading the authors to conclude that scores on this factor may capture features that are specific to psychopathy, distinguishing core psychopathy from other diagnostic definitions.

\section{Assessment and treatment of offenders with high-functioning autism-spectrum disorders}

As the number of people diagnosed with Asperger syndrome is increasing (partly due to increased awareness among the public and professionals), this is likely to lead to a concurrent increase in the number of those in forensic establishments who are recognised as having the syndrome.

A report by the Royal College of Psychiatrists (2006) outlines training for psychiatrists in the diagnosis and management of autism-spectrum disorders. In the next sections we discuss diagnosis and treatment in forensic populations (Box 2).

BOX 2 Diagnosis, treatment and risk in offenders with Asperger syndrome

Diagnosis

- Routine use of screening instruments among forensic populations

- Diagnostic assessments (e.g. ADI-R, ADOS-G, AAA)

Treatment

- The right therapeutic milieu

- Pharmacological treatment of comorbid psychiatric problems

- Psychological interventions: CBT, art or music therapy to address issues of victimisation/resentment

\section{social skills training}

empathy skills training using $\mathrm{CBT}$, role playing or interactive software ('Mind Reading')

CBT to reduce harmful preoccupations, anxiety, depression

- Education and employment

Risk assessment and management

- Autism-specific risk assessments

- Gradual transfer to less secure or community placements 


\section{Diagnosis}

Diagnosing Asperger syndrome in adults is complicated by a number of difficulties, including selective improvement in social impairment, comorbid psychiatric disorders and lack of a reliable developmental history. To overcome these, professionals working in prisons and secure units could make routine use of a brief screening instrument such as the Nylander questionnaire (Hare 1999). If this suggests that a patient may have Asperger syndrome, a diagnostic assessment could follow.

A carefully conducted clinical interview, along with a full history of the person's social, communicative and behavioural development obtained from an informant who knew the person well in their formative years, is crucial in establishing the diagnosis of Asperger syndrome. Alternatively, there are a number of semistructured diagnostic and screening assessments available, but these only approximate good clinical judgements.

Among individuals with high-functioning autism, the diagnosis is less likely to have been made during childhood, and identifying a 'reliable' informant who can recall important details of early childhood behaviour can be difficult. Where a 'definite' diagnosis cannot be made, management should be dictated by current need: a lack of a certain diagnosis should not preclude access to services that may be helpful and facilitate social inclusion (Murphy 2003). Although the Autism Diagnostic Interview - Revised (ADI-R; Lord 1994) and the Autism Diagnostic Observation Schedule - Generic (ADOS-G; Lord 2000), designed for children, may be useful for diagnostic assessment in adulthood, the Adult Asperger Assessment (AAA; BaronCohen 2005) has been specifically created to be used for the diagnosis in adults.

\section{Therapeutic milieu}

There is currently little research to inform the development of appropriate services for offenders with autism. Offenders are being treated by various psychiatric subspecialties, reflecting local circumstances rather than the needs of the patients themselves (Woodbury-Smith 2005). The Hayes' Unit in Bristol, run by the National Autistic Society, provides specialist care for mentally disordered offenders with high-functioning autism-spectrum disorder. Facilities are also available in a small number of private secure units.

In treating people with Asperger syndrome, maintaining the right therapeutic milieu is important. The environment (people, buildings and programmes) should be structured and predictable. Stimuli should be 'low arousal' and an adequate number of staff should be trained in managing autism-spectrum disorders (Royal College of Psychiatrists 2006). People with Asperger syndrome may find it difficult to articulate their anxieties, leading to aggressive behaviour, especially in the event of changes to their routine, ward staffing patterns or living environment. Staff working with them can compensate for this alexithymia by being sensitive to early signs of distress. Ward staff especially need support in dealing with the peculiarities of caring for patients with Asperger syndrome, who can appear 'challenging' when they are confronted with even minor changes.

Given the relatively small number of offenders with Asperger syndrome, consideration should be given to creating the therapeutic environment in dedicated ward areas of medium or low secure units; less disturbed patients might be treated on long-stay rehabilitation wards. This would entail the special training of staff to care for these individuals within local services, closer to the patient's place of residence (Woodbury-Smith 2006). Although any such service development would be for a minority subgroup of the offender population, it is justifiable from a humane, as well as from a therapeutic, perspective. Additionally, there is a high financial cost involved in detaining even a very small number of patients inappropriately for long periods in high secure hospitals. If a patient is more socially impaired, a placement within a learning disability (intellectual disability) service may be more appropriate (Royal College of Psychiatrists 2006; Woodbury-Smith 2006).

\section{Pharmacological treatment of comorbid psychiatric conditions}

Comorbidity in Asperger syndrome is relatively common, with an increased prevalence of anxiety, depression, sleep problems and other developmental disorders (e.g. Tourette syndrome, attention-deficit hyperactivity disorder) (Woodbury-Smith 2008). Pharmacological interventions can be useful (Royal College of Psychiatrists 2006). Although no studies have examined the efficacy of existing agents when used specifically for comorbidity in Asperger syndrome, it seems reasonable to expect that their beneficial (and unwanted) effects would be similar to those reported in comparable populations. Studies involving children with 'core autism' have indicated that those with symptoms such as hyperactivity, rigidity and irritability may benefit from medication (McDougle 1996; Research Units on Pediatric Psychopharmacology 2002, 2005). 


\section{Psychological treatment}

Psychological interventions play an important role in the rehabilitation of people with autism. Some of the factors described above, including the individual's feelings of marginalisation, victimisation and resentment, may become evident only after a long period of work, when a therapeutic relationship has been built up. Techniques such as cognitive-behavioural therapy (CBT) may be useful in addressing the underlying problems that have been identified. It may also be beneficial in reducing preoccupation with violent and sexual themes (Barry-Walsh 2004) and in the management of anxiety and depression (Attwood 2007), both of which have been associated with an increased risk of aggression (Blair 2005). Some people with Asperger syndrome find 'talking therapy' difficult and may prefer art or music therapy. In some circumstances, assessment of the individual's neuropsychological strengths and vulnerabilities may be more pertinent to management.

There is no evidence that a psychoanalytic approach is helpful.

Social skills training may be beneficial in rehabilitation. Very few studies have examined its usefulness in Asperger syndrome, but social skills training groups provide the opportunity to address a number of factors that might be associated with problematic behaviour. Although there are no hard and fast rules as to how 'social groups' should be run, they should be small and each meeting should be held in the same place and at a regular time. Issues such as how to behave in different circumstances and the provision of 'social scripts' are likely to be an integral part. Techniques to manage intrusiveness (and perhaps social inappropriateness) of circumscribed interests may also feature.

The ability to empathise is widely believed to protect individuals from victimising others (Farrington 2007), and the lack of empathy has been implicated as an underlying reason for offending by people with Asperger syndrome (Wing 1981; Woodbury-Smith 2005). Techniques to target low empathy in the offender populations include cognitive-behavioural skills training (Farrington 2007), role-playing and using interactive software. For instance, 'Mind Reading', an interactive guide to emotions, was found to significantly improve the ability of adults with Asperger syndrome to recognise a variety of complex emotions and mental states over a period of 10-15 weeks (Golan 2006).

\section{Employment}

Unemployment is a risk factor for offending, as individuals are more likely to offend during periods without work (Farrington 2007). Some secure units provide specialist occupational therapy in view of the particular difficulties that mentally disordered offenders have in finding suitable employment as a result of their criminal and psychiatric histories. These employment specialists liaise with colleges in identifying suitable educational courses. Individuals with Asperger syndrome could be helped to identify training programmes, and subsequently jobs, that provide a regular routine with sympathetic employers.

Occupational therapists may also help such individuals identify and pursue pastimes that would help reduce the anxiety often experienced with the syndrome.

\section{Prognosis and recidivism}

A study by Hare and his colleagues revealed that offenders with autism-spectrum disorders spend more time (on average 11.26 years) in high secure settings than offenders with other psychiatric disorders (Hare 1999). This may relate to lack of less secure or community provisions to which they can be discharged. The relatively longer stay may be responsible for the 'overrepresentation' of patients with Asperger syndrome in English high secure units. Hare et al therefore recommended the development of autism-sensitive risk assessments. These assessments should take into account the circumstances or individual reasons for the criminal behaviour (Wing 1997), in particular the role of circumscribed interests in past offences, previous attempts at forming romantic relationships through stalking, and indecent exposure, as well as 'clinical' risk factors (Box 3).

People with autism-spectrum disorders held in secure units are more vulnerable to exploitation, bullying and intimidation by virtue of their 'oddness' and social naivety. The risks (both to themselves and other people) arising from these factors are compounded by their inability to articulate their frustrations appropriately. Risk assessment should therefore take into account any factors that were protective against aggressive outbursts before incarceration.

\section{BOX 3 Clinical risk factors to which offenders may be exposed}

- Life events, including changes to the person's established routine

- Influence of potentially antisocial other person

- Unstable living circumstances

- Renewed interest in morbid preoccupation

- New interest in the pursuit of intimate relationships 


\begin{tabular}{lllll}
\multicolumn{5}{l}{ MCO answers } \\
1 & 2 & 3 & 4 & 5 \\
af & at & af & af & af \\
bf & bf & bf & bf & bf \\
cf & cf & ct & cf & cf \\
dt & df & df & dt & dt \\
ef & ef & ef & ef & ef
\end{tabular}

A mentally disordered offender's stable behaviour in a secure environment is often used as a marker of their progress. However, Wing (1997) pointed out that patients with Asperger syndrome who behave in an exemplary manner in a particular environment may reoffend if they are transferred to a less appropriate setting or an unfamiliar one with a new set of rules and routines. The milieu (as described earlier) of the future placement is crucial in managing risk in offenders with Asperger syndrome. Among this group of offenders, a lack of comprehension of the consequences of their criminal behaviour and their egocentric justification of their acts further increase the risk of reoffending following transfer to less secure conditions or discharge into community placements (Wing 1997; Hare 1999).

The peculiar risk issues and recidivism rate underline the need to identify patients with Asperger syndrome in secure units. If a change in placement is envisaged, it may be important to allow such individuals plenty of time beforehand to become familiar with key professionals who will take over their care, as they are likely to find working with unfamiliar professionals even more daunting than changes to the physical environment.

\section{Legal issues}

For individuals with autism-spectrum disorders who come into contact with the criminal justice system, it is important to recognise the potential impact of the disorders on criminal responsibility, mental capacity, fitness to plead and the ability to bear witness (Royal College of Psychiatrists 2006). The literature concerned with these important issues is wholly inadequate. For example, in relation to mens rea it might be argued that some people with Asperger syndrome have an understanding of the consequences of their actions that is inadequate for them to be held morally (or criminally) responsible for their offending (BarryWalsh 2004; Schwartz-Watts 2005). It has also been argued that the broad capacity required by US courts to establish fitness to plead would be difficult to establish in many people with Asperger syndrome (Barry-Walsh 2004). Similar concerns arise when applying the criteria in British courts to this group of defendants. Further research and discussion is urgently needed to provide clinicians with guidance when faced with making such decisions.

\section{Future research}

There is an urgent need for further research of a clinical nature within the offender population. More specifically, the prevalence of Asperger syndrome among those detained in medium and low secure psychiatric services is needed to inform the development of services for the vast majority of offenders with the syndrome who find themselves detained for longer than necessary because of the lack of knowledge of methods of rehabilitation. To be effective, such research will need to examine the benefits of specialist interventions and the limitations of generic therapeutic programmes for forensic rehabilitation. It is hoped that mental health clinicians will then be equipped to make an effective contribution to the social inclusion of people with Asperger syndrome and to make their rehabilitation more effective.

\section{References}

Allen D, Evans C, Hider A, et al (2007) Offending behaviour in adults with Asperger syndrome. Journal of Autism and Developmental Disorders; 38 : 748-58.

American Psychiatric Association (1994) Diagnostic and Statistical Manual of Mental Disorders (4th edn) (DSM-IV). APA.

Attwood T (2007) The Complete Guide to Asperger's Syndrome. Jessica Kingsley Publishers.

Baron-Cohen S, Wheelwright S, Robinson J, et al (2005) The Adult Asperger Assessment (AAA): a diagnostic method. Journal of Autism and Developmental Disorders; 35: 807-19.

Barry-Walsh JB, Mullen PE (2004) Forensic aspects of Asperger's syndrome. Journal of Forensic Psychiatry and Psychology; 15: 96-107.

Blair J, Mitchell D, Blair K (2005) The Psychopath: Emotion and the Brain. Blackwell Publishing.

Crocombe J, Mills R, Wing L, et al (2006) Autism Spectrum Disorders in the High Security Hospitals of the United Kingdom. A Summary of Two Studies. The National Autistic Society (http://www.Idoffenders.co.uk/ filefinder.htm).

Elvish J (2007) The exploration of autistic spectrum disorder characteristics in individuals within a secure service for people with learning disabilities. Thesis for Doctorate in Clinical Psychology. The Tizard Centre, University of Kent.

Farrington DP (2007) Childhood risk factors and risk-focused prevention. In The Oxford Handbook of Criminology (4th edn)(eds M Maguire, R Morgan, R Reiner): 602-40. Oxford University Press.

Frith U (ed) (1991) Asperger and his syndrome. In Autism and Asperger Syndrome: 1-36. Cambridge University Press.

Golan 0, Baron-Cohen S (2006) Systemizing empathy: teaching adults with Asperger's syndrome or high-functioning autism to recognize complex emotions using interactive multimedia. Development and Psychopathology; 18: 591-617.

Hare DJ, Gould J, Mills R, et al (1999) A preliminary study of individuals with autistic spectrum disorders in three special hospitals in England. National Autistic Society (http://www.nas.org.uk/content/1/ c4/38/68/3hospitals.pdf)

Hawes V (2003) Developmental disorders in prisoners volunteering for DSPD assessment. In Proceedings of the 2nd International Conference on the Care and Treatment of Offenders with a Learning Disability (eds C Dale, L Storey): in Presentations on 'Working with offenders' (http://www.Idoffenders.co.uk/filefinder.htm\#d).

Klin A, McPartland J, Volkmar FR (2005) Asperger's syndrome. In Handbook of Autism and Pervasive Developmental Disorders (eds FR Volkmar, A Klin, R Paul, et al): 88-125. Wiley.

Lord C, Rutter M, LeCouteur A (1994) The Autism Diagnostic ScheduleRevised: a revised version of a diagnostic interview for caregiver of individuals with possible pervasive developmental disorders. Journal of Autism and Developmental Disorders; 24: 659-85. 
Lord C, Risi S, Lambrecht L, et al (2000) The Autism Diagnostic Observation Schedule-Generic: a standard measure of social and communication deficits associated with the spectrum of autism. Journal of Autism and Developmental Disorders; 30: 205-23.

McDougle CJ, Naylor ST, Cohen DJ, et al (1996) A double-blind, placebocontrolled study of fluvoxamine in adults with autistic disorder. Archives of General Psychiatry; 53: 1001-8.

Mouridsen SE, Rich B, Isager T, et al (2008) Pervasive developmental disorders and criminal behaviour: a case control study. International Journal of Offender Therapy and Comparative Criminology; 52: 196205.

Murphy D (2003) Admission and cognitive details of male patients diagnosed with Asperger's Syndrome detained in a Special Hospital: comparison with a schizophrenia and personality disorder sample. Journal of Forensic Psychiatry and Psychology; 14: 506-24.

Murphy D (2007) Hare Psychopathy Checklist Revised profiles of male patients with Asperger's syndrome detained in high security psychiatric care. Journal of Forensic Psychiatry and Psychology; 18: 20-126.

Myers F (2004) On the Borderline? People with Learning Disabilities and/ or Autistic Spectrum Disorders in Secure, Forensic and Other Specialist Settings. Scottish Development Centre for Mental Health (http://www. scotland.gov.uk/Resource/Doc/47251/0023734.pdf).

Research Units on Pediatric Psychopharmacology (2002) Risperidone in children with autism and serious behavioral problems. New England Journal of Medicine: 347: 314-21.

Research Units on Pediatric Psychopharmacology (2005) Randomized, controlled, crossover trial of methylphenidate in pervasive developmental disorders with hyperactivity. Archives of General Psychiatry; 62: $1266-74$.

Royal College of Psychiatrists (2006) Psychiatric Services for Adolescents and Adults with Asperger Syndrome and Other Autistic-Spectrum Disorders (Council Report CR136). Royal College of Psychiatrists (http:// www.rcpsych.ac.uk/files/pdfversion/cr136new.pdf).
Schwartz-Watts DM (2005) Asperger's disorder and murder. Journal of the American Academy of Psychiatry and the Law, 33: 390-3

Scragg P, Shah A (1994) Prevalence of Asperger's syndrome in a secure hospital. British Journal of Psychiatry; 165: 679-82.

Siponmaa L, Kristiansson M, Jonsson C, et al (2001) Juvenile and young adult mentally disordered offenders: the role of child neuropsychiatric disorders. Journal of American Academy of Psychiatry and the Law, 29: 420-6.

Soderstrom H, Nilsson T, Sjodin AK, et al (2005) The childhood-onset neuropsychiatric background to adult psychopathic traits and personality disorders. Comprehensive Psychiatry; 46: 111-6.

Viding EM (2007) Re: The callous unemotional traits (e-Letter). British Journal of Psychiatry; 29 May (http://bjp.rcpsych.org/cgi/eletters/190/49/ s33\#3699)

Wing L (1981) Asperger's syndrome: a clinical account. Psychological Medicine: 11: 115-29.

Wing L (1997) Asperger's syndrome: management requires diagnosis. Journal of Forensic Psychiatry; 8: 253-7.

Woodbury-Smith MR, Clare ICH, Holland AJ, et al (2005) A case-control study of offenders with high-functioning autistic spectrum disorders. Journal of Forensic Psychiatry and Psychology; 16: 747-63.

Woodbury-Smith MR, Clare ICH, Holland AJ, et al (2006) High functioning autistic spectrum disorders, offending and other law-breaking: findings from a community sample. Journal of Forensic Psychiatry and Psychology; 17: 108-20.

Woodbury-Smith MR, Volkmar FR (2008) Asperger Syndrome: a review. European Journal of Child and Adolescent Psychiatry; 56: 1-11.

Woodbury-Smith MR, Clare ICH, Holland AJ, et al (2009) Circumscribed interests among offenders with autistic spectrum disorders: a casecontrol study. Journal of Forensic Psychiatry and Psychology; in press.

World Health Organization (1992) The ICD-10 Classification of Mental and Behavioural Disorders: Clinical Descriptions and Diagnostic Guidelines. WHO

\section{MCOs}

1 Regarding offenders with Asperger syndrome in high secure units:

a the majority are transferred as sentenced prisoners

b the majority have committed sexual offences

c in most cases the index offences have taken place in the context of substance misuse

d the majority are transferred prior to sentencing

e the majority are detained under the mental health category of mental impairment.

\section{Hans Asperger originally referred to Asperger syndrome as:}

a autistic psychopathy

b high-functioning autism-spectrum disorder

c schizoid personality of childhood

d non-verbal intellectual disability

e schizotypal disorder.

\section{Research suggests that offenders with} Asperger's syndrome are:

a less likely to commit violent offences

b more likely to commit offences of a sexual nature

c more likely to commit fire-setting offences

d more likely to commit drug offences

e more likely to commit fraud.

4 The Hayes Unit is:

a a high secure unit in England

b a therapeutic prison for offenders with Asperger syndrome

c the healthcare wing of HMP Whitemoor

$\mathrm{d}$ the dangerous severe personality disorder unit

in Broadmoor Hospital

e a specialist unit for mentally disordered offenders with a high-functioning autismspectrum disorder
5 Regarding psychopathy in offenders with Asperger syndrome:

a a few offenders received an overall score amounting to a diagnosis of psychopathy

$b$ the mean PCL-R score in offenders with Asperger syndrome was significantly lower than other offenders in Broadmoor Hospital

c offenders with Asperger syndrome frequently received higher scores in the antisocial domain of the PCL-R

$d$ the mean PCL-R score in the Asperger syndrome sample was comparable to other offenders in Broadmoor Hospital

e this has so far not been researched. 